\title{
Combined optimisation and process integration techniques for the synthesis of fuel cells systems
}

\author{
Julien Godat, François Marechal \\ Laboratory of Industrial Energy Systems, Institute of Energy Sciences, \\ Swiss Federal Institute of Technology , CH-1015 Lausanne \\ mailto:francois.marechal@epfl.ch, \\ tel + 412169335 16, fax +41216933502
}

\begin{abstract}
A method that combines process modelling and process integration techniques has been developed to tackle the design of complex integrated systems like fuel cell systems. This method uses the equations of the composite curves as constraints to model the ideal heat exchanger network and the corresponding utility system. When combined with the use of process modelling techniques, this method allows to synthesize optimized fuel cell integrated systems with high efficiency and that integrates the technological design constraints.
\end{abstract}

\section{Introduction}

The physical principles behind a fuel cell system is the electrochemical conversion of a fuel into electricity. If the membrane system that allows the separate transfer of the ions and the electrons is the heart of the system, the system integration is of major importance with respect to the system performances(Hirschenhofer , 1998). The Ballard Proton Exchange Membrane Fuel Cell (PEMFC) system (Keitel, R.,) has been used as a basis for this study. It includes a fuel processing system, the fuel cell and the post combustion sub-system. The fuel processing section converts the fuel into a suitable form for the electrochemical reaction, avoiding catalyst poisoning and featuring acceptable catalyzed reaction rates. The fuel processing is a steam reforming system operating at a pressure of 3 bar followed by a shift reactor that converts $\mathrm{CO}$ of the reformate into additional $\mathrm{CO}_{2}$ and $\mathrm{H}_{2}$ and a Preferential oxidation reactor (PROX) that converts the remaining $C O$ to avoid fuel cell catalyst poisoning. In our study, we did consider a medium temperature $\left(250^{\circ} \mathrm{C}\right)$ shift reactor that allows shift reaction to be realized in one step. A $H_{2}$ loss by oxidation has been considered in the PROX reactor due to the selectivity of the catalyst. The fuel cell operates at low temperature (less than $100^{\circ} \mathrm{C}$ ). The hydrogen crossing the membrane produces electricity by the electrochemical conversion of the free energy of the hydrogen oxidation reaction. The fuel conversion being lower than $100 \%$, The remaining fuel will be recovered by post combustion to satisfy the energy requirement of the system. In order to reach the operating pressure of the system, the air is compressed by a turbo-compressor driven by the expansion of the flue gases resulting from the post combustion. Coupling 


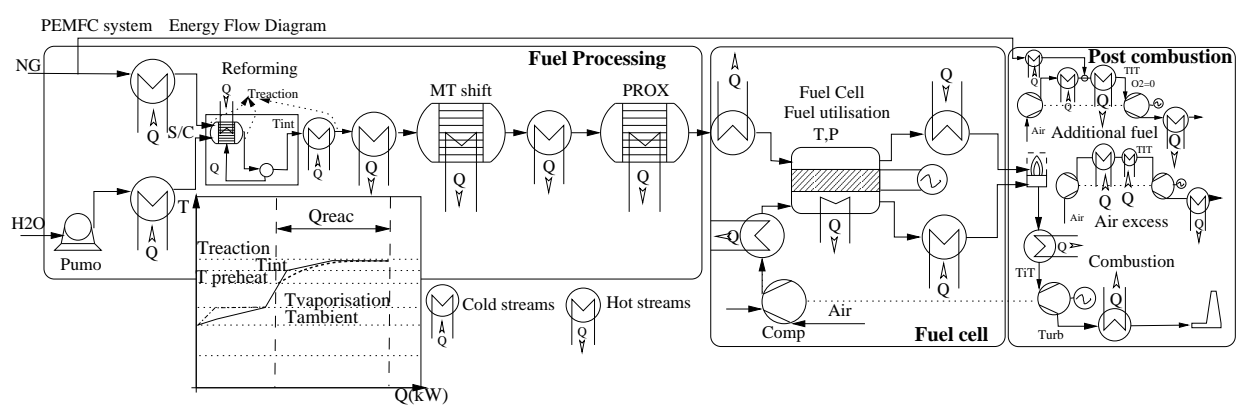

FIG. 1. Energy flow diagram of the system

of a electricity generator allows producing an additional amount of electricity whose production will depend on the turbine inlet temperature $T i T$ and on the gas turbine system integration. Process integration in fuel cell systems concerns therefore different levels. In terms of chemical conversion, the fuel processing performances affect the fuel cell and the post combustion efficiency, but also in terms of combined heat and power production. A characteristic of the fuel cell system design is the heat exchange system that can not be considered as a conventional network of individual heat exchangers but as a system where heat exchanges take place simultaneously with the chemical and the electrochemical reactions in the same vessel. Fronted with this multi-scale integration problem, our goal has been to develop a methodology that combines process modelling, process integration and optimisation techniques to design better integrated fuel cell systems.

\section{Process synthesis methodology}

The first step of the process synthesis methodology is the generation of a simulation model based on the Energy Flow Diagram (fig 1). Knowing the values of the decision variables $(\mathrm{P})$, the energy flow model is used to compute the temperatures, pressures, flowrates and energy flows that define the system requirements. In the integration strategy, some of the flowrates $\left(\dot{m}_{u}\right)$ have to be computed to close the energy balance and satisfy the heat cascade of the integrated system, we refer to these as being the utility system. The temperatures, pressure and specific energy flows of the utility sub-systems are also computed by energy flow modelling when these are related to decision variables (e.g. the operating pressure or $T i T$ ). The flowrates will be computed by process integration using the Effect Modelling and Optimisation (EMO) approach (Marechal and Kalitventzeff (1998)). The "ideal but feasible at an acceptable cost" heat exchanger network model is formulated as a linear programming (LP) problem including the heat cascade as constraints and the process efficiency as an objective function. The results of the LP optimisation are then used to compute the objective function of the design and to define the optimal values of the decision variables $(\mathrm{P})$ that maximize the efficiency. In our study, the objective function is the energy efficiency of the system, computed by (1) and the optimisation is stated as (2), where $\dot{m}_{u}(P)$ is the solution of the LP problem (3).

$$
\eta_{e}\left(P, \dot{m}_{u}\right)=\frac{\dot{E}_{F C}(P)+\dot{E}_{G T}\left(P, \dot{m}_{u}\right)-\dot{m}_{O_{2}}(P) * \dot{E}_{O_{2}}}{\dot{m}_{F C} * L H V_{N G}+\dot{m}_{N G_{a d d}}\left(P, \dot{m}_{u}\right) * L H V_{N G}}
$$


where $\dot{E}_{F C}(P)$ and $\dot{E}_{G T}\left(P, \dot{m}_{u}\right)$ are respectively the electricity production by the fuel cell system and the net production of the integrated gas turbine system for the decision variables $\mathrm{P}$ and the utility flowrates $\dot{m}_{u}$. The natural gas (with a lower heating value $L H V_{N G}$ ) flowrate entering the fuel processing section $\left(\dot{m}_{F C}\right)$ is a constant, while $\dot{m}_{N G_{a d d}}\left(P, \dot{m}_{u}\right)$,the additional natural gas in the utility system results from the LP problem (3). $\dot{m}_{\mathrm{O}_{2}}(P)$ is the pure oxygen flow used in the PROX reactor for the decision variables $\mathrm{P}$ and $\dot{E}_{\mathrm{O}_{2}}$ is the energy consumption of the pure oxygen used in the system $\left(300 \mathrm{kWh} /\right.$ ton of $\left.\mathrm{O}_{2}\right)$.

$$
\begin{gathered}
\operatorname{Min}_{P}\left(P, \dot{m}_{u}(P)\right) \\
\operatorname{Min}_{\dot{m}_{u}} F_{L P o b j}\left(\dot{m}_{u}, P\right)=\dot{m}_{N G_{a d d}}\left(P, \dot{m}_{u}\right) * L H V_{N G}-\dot{E}_{G T}\left(P, \dot{m}_{u}\right)
\end{gathered}
$$$$
\text { Subject to Heat cascade constraint }
$$$$
\text { Mechanical power balance }
$$

In the adopted approach, the model are solved as a simulation problem with enough robustness solving only part of the problem by linear optimisation and analysing the sensitivity of the decision variables $(\mathrm{P})$. This allows not only identifying the optimum but also to represent the shape of the search space.

\subsection{Process Energy Flow model}

The Energy flow model concerns the calculation of the chemical and electro-chemical reactions as well as the heat exchange requirements, the separation units, compression and expansion. The model has been developed using an equation solver approach (Belsim $\mathrm{s}, \mathrm{a}$, , 2001). Although this choice is not critical, it allows an easy modification of the list of specifications during the model development without having to redesign the solving sequence as it would have been the case in the sequential approach. The definition of the hot and cold streams in the energy flow model is critical and should be considered carefully if we do not want to miss energy savings potentials. In the conventional system, the steam is produced in a separated heat exchanger before being mixed with the fuel at the inlet of the reformer (dotted line at the vaporisation temperature on the composite curve of figure 1). In order to recover the partial pressure effect of the steam injection, the energy requirement of the feed preheating has been considered as a liquid-vapour mixture of water and natural gas to be heated up (plain line on the same figure). This implies the use of a special heat exchange equipment. The chemical reactions are modelled assuming (where appropriate) equilibrated reactions. In order to account for the catalyst efficiency, the equilibrium is computed at a different temperature from the heat balance one. The conventional representation of the reformer is to consider the feeds preheating up to the present temperature and then to consider a cold stream representing the heat of reaction Qreac at the constant reforming temperature Treac. In order to better fit the reactor temperature profile, we considered the feed stream preheating to Treac, then the reaction takes place to reach equilibrium at Treac. The heat of reaction is considered into parts : 
a cold stream from Tint (the reaction startup temperature) to Treac corresponding to the reaction products heating and the balance at constant temperature Treac. This approach will better approximate the real temperature profile in the reactor (dotted line of figure 1) and will allow energy savings for example by additional feed preheating. This definition of heat requirement of the reforming reaction should be kept in mind when it will be necessary to compute the heat exchange network, especially if a pinch point appears in the corresponding temperature range. A similar approach has been used to model the energy requirement of the exothermic reactions (shift and preferential oxidation, combustion as well as the fuel cell it self).

For the system optimisation, the pressure, the steam to carbon ratio and the reforming temperature have been considered as decision variables while the temperature of the shift reactor, as well as the conversion in the PROX reactor have been considered as fixed. The fuel utilisation in the fuel cell has not been optimised in our study. The post combustion is modelled assuming the stoechiometric combustion of the fuel not converted in the fuel cell (this fuel contains the remaining methane and hydrogen). The resulting flue gases are then expanded in a turbine with an inlet temperature (TiT) considered as a decision variable. It should be noted that the heat requirement associated with the combustion assumes the possible air and fuel preheatings and the high temperature exchange of the combustion products with the reformer.

\subsection{The utility system}

In order to balance the heat requirement of the system, a utility system will be used. According to the decision parameters, two situations may occur : 1) the heat of the post combustion is not sufficient to balance the heat requirement of the system and additional firing is needed or 2) the system is balanced by the heat of the post combustion and actions have to be taken in order to use the energy excess. These two situations will be represented by adding the two sub-systems in the problem presented on the right of figure 1 (Post combustion sub-system). On the top, the sub-system represents the additional fuel added to the post combustion in order to balance the composite curve, this leads to an additional air requirement (that flows through the compressor, the fuel cell and the air preheating section) and, in the center, an air excess that will be computed in order to maximise the energy conversion into net electricity using the Brayton cycle. The bottom of the figure represents the post combustion of the non converted fuel. The model used for this representation has been presented in (Marechal and Kalitventzeff , 1998) and has been adapted to account for the effect of the oxygen partial pressure on the electricity production in the fuel cell. This model represents the derivative of the additional fuel and the air excess in the composite curve constraints and the objective function. The limit of this configuration will be a renegerative gas turbine operating at a pressure of $3 \mathrm{bar}$, without the fuel cell system reaching $26 \%$ of electrical efficiency. The model used will allow to represent the possible regenerative exchange, not only between the streams of the gas turbine system, but also with the streams of the process. The difficulty of applying the heat cascade model lies on the fact that it can only be solved by solving an optimisation problem : the solution being defined by the activation of inequality constraints : pinch point or utility flowrate. 


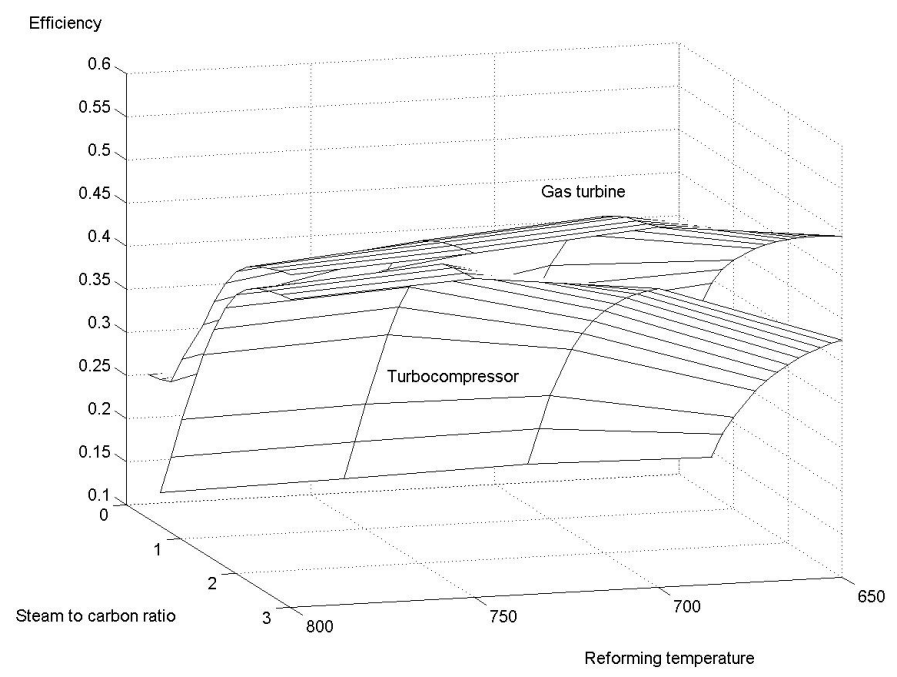

FIG. 2. System efficiency as a function of reforming temperature and steam to carbon ratio with and without net production of electricity with the gas turbine

\section{Results}

The visualisation of the objective function with respect to some of the decision parameters is shown on figure 2. Two situations are presented as a function of the reforming temperature and the steam to carbon ratio. The first (lower surface) represents the turbocompressor solution where the $T i T$ is such that the expansion turbine will only drive the compressor without net production of electricity (as it is the case in the original design), while the second (upper) assumes a net electricity production by the gas turbine. The optimal efficiency computed for the system is of $53 \%$, obtained for a steam to carbon ratio of 4 and a reforming temperature of $700^{\circ} \mathrm{C}$ for the gas turbine case. For the turbo compressor case, the optimum efficiency is of $47 \%$ with a reforming temperature of $750^{\circ} \mathrm{C}$. These values have to be compared with an efficiency of $36 \%$ in the original design. It should be mentioned that the optimal decision are quite different in the two situations indicating that the investment and the choice of the catalyst will be affected by the configuration decision. More results are presented in (Godat and Marechal , 2002). According to design assumptions or limits, the activation of different pinch points, that results from the LP optimisation strategy, will lead pratically to different configuration. Considering as an example the composite curves of figure 3 that have been computed for the same steam to carbon and reforming temperature. On the right, we consider system without electricity production by the gas turbine (turbo-compressor). In this situation, the liquid-vapour feed mixture preheating is necessary in order to reach high system efficiency. Producing steam in a separate heat exchanger (doted cold composite) would have activated a pinch point that would have increased the additional firing requirement. The mixture preheating leads to an increase of $1 \%$ of efficiency (from $44.1 \%$ to $45.2 \%$ ). On the left of the figure, we present the results of the regenerative gas turbine integration allowing electricity generation by the gas turbine. In this case, the shape of the composite curve indicates that both 

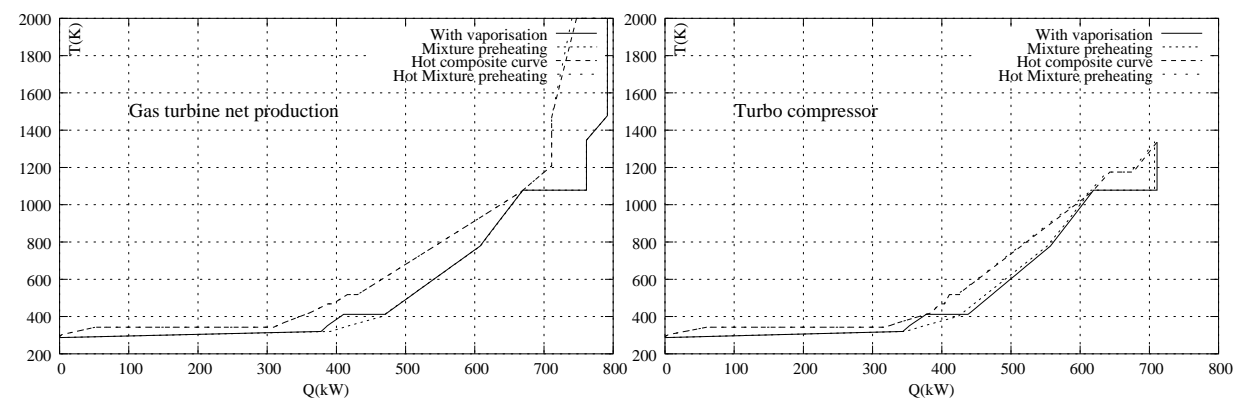

FIG. 3. Composite curves of the system with and without net production with the gas turbine for a) $T_{\text {ref }}=800^{\circ} \mathrm{C}, \mathrm{S} / \mathrm{C}=2.6$ and b) $T_{\text {ref }}=800^{\circ} \mathrm{C}, \mathrm{S} / \mathrm{C}=2.6$

separate production of steam (doted cold composite) and mixture preheating may be envisaged without efficiency penalty. In this case, the system efficiency is of $47.8 \%$. This sensitivity analysis has been made because the objective function (the efficiency) is not the only concern. Other design parameters for example the humidity in the fuel cell and of course the investment have also to be analysed.

\section{Conclusion}

A model based on the combined use of modelling and process integration techniques has been developed to design optimal integrated fuel cell systems. The use of the process integration techniques solved as a linear programming problem allows modelling the heat exchanges in the integrated system and determining the flowrates in the system even if the pinch point position changes. This approach is especially useful to design integrated systems because it allows modelling the heat exchange system without defining a priori its structure. The proposed modelling method is a first step of the synthesis methodology that will integrate multiple objectives (i.e. the efficiency and the cost) in order to finally design the best system structure. Compared to simultaneous simulation and optimisation, the use of a two level approach (solving the model at a lower level), allows not only the identification of the optimal decision parameters but also the characterisation of the optimal region for the system configurations.

\section{Références}

Hirschenhofer J.H., Fuel Cell Handbook, Fourth Edition, (1998)

Godat J., Marechal F., Optimization of a fuel cell system using process integration techniques, Fuel cell conference, Amsterdam, 2002,submitted the Journal of Power Sciences, (2002)

Marechal F., Kalitventzeff B., Process integration : Selection of the optimal utility system Computers and Chemical Engineering, Vol 22 Suppl., pp. S149-S156, (1998)

Keitel, R., 1996, Application with Proton Exchange Membrane (PEM) Fuel Cells for deregulated market place, ALSTOM BALLARD, Frankfurt, Germany.

Belsim - Vali III, v10 User Guide, Belsim s.a., Rue Georges Berotte, 29A, B-4470 SaintGeorges-sur-Meuse (Belgium), http ://www.belsim.com. (2001) 